\title{
Mapeando a eficiencia no consumo da auga
}

Soto, Manuel'; Varela-García, Francisco-Alberto; Torrijos, Verónica³; Calvo, Domingo ${ }^{4}$

'Dept. Química, Facultade de Ciencias UDC, ORCID 0000-0002-4843-556X

${ }^{2}$ Dept. Enxeñaría Civil, ETSE Camiños, Canais e Portos UDC,

ORCID 0000-0001-9705-2154

${ }^{3}$ Oficina de Medio Ambiente UDC, ORCID 0000-0001-7042-4456

${ }^{4}$ Vicerreitor de Economía, Infraestruturas e Sustentabilidade UDC

\section{RESUMO}

A enquisa sobre o consumo de auga desenvolta polo Emapic e a Oficina de Medio Ambiente da UDC é unha ferramenta en liña que ten por obxectivos crear o mapa da eficiencia no consumo de auga na Galiza e no mundo, aumentar a concienciación da poboación e reducir o gasto de auga mediante hábitos e equipamentos máis eficientes. Con metodoloxía sinxela no rexistro en vivendas e edificios públicos, fai uso das TIC para mellora da aprendizaxe de conceptos de sustentabilidade ambiental, fomentando hábitos de consumo responsábel. Unha vez feita a enquisa, a persoa participante recibe información e recomendacións para 0 aforro de auga, así como a comparación cos datos acumulados. Activa desde abril de 2018, conta actualmente con 150 rexistros, que poden referirse a un único baño, p.ex. vivenda, ou a todos os equipamentos dun edificio público, p.ex. facultade. Desta forma, xa inclúe 250 billas e 184 cisternas. Os resultados pódense consultar de forma libre e analizar segundo diferentes criterios: caudal medio das billas, tipo de cisternas, existencia de información para uso responsábel, presenza de sistemas aforradores de auga. A ferramenta é de especial utilidade para a educación ambiental e social, tanto non formal como en calquera dos niveis educativos, e para a xestión da auga nos ámbitos institucionais. Debería servir tamén para poñer en evidencia a entidades que seguen introducindo equipamentos ineficientes que derraman a auga que non temos.

PALABRAS CHAVE: Auga, consumo, mapa participativo, TIC. 


\section{CITA RECOMENDADA:}

Soto, Manuel; Varela-García, Francisco-Alberto; Torrijos, Verónica; Calvo, Domingo (2020): Mapeando a eficiencia no consumo da auga. En De la Torre Fernández, E. (ed.) (2020). Contextos universitarios transformadores: Boas prácticas no marco dos GID. IV Xornadas de Innovación Docente. Cufie. Universidade da Coruña. A Coruña (págs. 383 -402).

DOI capítulo: https://doi.org/10.17979/spudc.9788497497756.338

DOI libro: https://doi.org/10.17979/spudc.9788497497756

\section{ABSTRACT}

The water consumption survey developed by Emapic and the Office for the Environment UDC is an online tool that aims to create the map of water consumption efficiency in Galiza and the world, to increase public awareness and to reduce water spending through more efficient habits and equipment. Using a simple methodology in the registration of homes and public buildings, it makes use of ICTs to improve the learning of concepts for environmental sustainability, promoting responsible consumption habits. Upon completion of the survey, the participant receives information and recommendations for water saving as well as comparability with accumulated data. Active since April 2018, it currently has 150 records, which can refer to a single toilet, e.g. housing, or all the equipment of a public building, e.g. faculty. Thus, it already includes 250 taps and 184 tanks. The results are accessible for free and can be analyzed according to different criteria: average flow rate of taps, type of tanks, existence of information for responsible use, presence of water-saving systems. The tool is especially useful for environmental and social education, at any non-formal and formal educational levels, and for institutional water management. It should also serve to highlight entities that continue introducing inefficient equipment that spills the water that we don't have.

KEYWORDS: Water, consumption, participatory map, ICT. 


\section{INTRODUCIÓN}

\subsection{CAMBIO CLIMÁTICO E USOS DA AUGA}

0 descontrol climático derivado do actual proceso de quecemento global trae consigo diversos eventos extremos, entre os que destacan as secas prologadas e máis frecuentes, e no caso galego tamén unha redución das precipitacións na estación seca (Díaz-Fierros, 2007). 0 recurso auga e os ecosistemas acuáticos sofren os principais impactos do cambio climático. As especies de auga doce mostran os maiores índices de perda de biodiversidade. A extrema seca de 2017 en toda Galiza foi motivo de todo tipo de novas nos medios de comunicación durante meses, e tamén centrou a atención de colectivos sociais e das institucións.

Galiza é coñecida como o pais dos mil ríos e no que a chuvia é abundante e todo está verde. Pero a realidade é que temos os ríos máis intervidos con presas eléctricas e encoros de abastecemento de todo 0 mundo (Martínez-Gil e Soto, 2006). E tamén unha perda de biodiversidade sen precedentes, que conta con varias especies completamente desaparecidas ou ao borde da extinción. Tanto os encoros como as simples captacións causan graves danos aos ríos, sobre todo nas épocas de seca. Os ríos deben o seu caudal ás chuvias, e o cambio climático trae secas máis frecuentes e intensas en Galiza. Neses momentos, calquera caudal de auga que saquemos dos ríos vai ter un forte impacto. Se o noso estilo de vida non é sustentable, se nos acomodamos ao uso de grandes cantidades de auga no día a día, se empresas e institucións non teñen tomado medidas para reducir a súa dependencia no uso da auga, a nosa resiliencia fronte a problemas climáticos de todo tipo serán menores. A polémica e as diverxencias sobre as medidas a adoptar no caso de escaseza de auga xurdiron durante a seca de 2017, particularmente na bisbarra de Vigo, propóndose unha nova detracción de caudal do río Verduxo para abastecer a cidade, que só se podería materializar detraendo caudal ecolóxico para servir a unha cidade na que se seguía a derramar auga en todo tipo de usos (Malvar et al., 2018). 


\subsection{CONSUMO DOMÉSTICO DE AUGA}

Segundo recomendan diferentes institucións, a cantidade de auga para unha vida digna sería duns 50 litros por persoa e día. Porén, o consumo de auga potable en Galiza atinxiu os 185 litros por habitante e día (IGE, 2018). Deste consumo, o 72\% corresponde aos fogares, con $138 \mathrm{~L} /$ persoa e día, 0 8\% aos usos municipais, e 0 20\% ás industrias, comercios e outras institucións.

Nos fogares, as actividades nas que se consume máis auga aparecen na seguinte orde:

- $\quad 50 \%$ no aseo persoal (ducha e lavabo)

- $20 \%$ no retrete

- $\quad$ 17\% na cociña (preparación de alimentos e lavado da louza)

- $\quad 10 \%$ na lavadora

- $3 \%$ noutros usos, como a limpeza da casa

No cuarto de baño consúmese máis de dúas terceiras partes do total de auga potable que entra nas casas. É por tanto o punto clave para tomar medidas de aforro. Séguelle en importancia a cociña. Unha sinxela ecoauditoría da auga (Soto, 2011), permite a medida dos consumos, a análise dos equipamentos e dos hábitos de uso da auga, e identificar as principais opcións de redución do consumo. Resultados para a área da Coruña mostraron un potencial para a redución a curto prazo de máis do $50 \%$ do consumo actual, mediante medidas de baixo custo, que combinan 0 cambio de hábitos e a instalación de redutores de caudal (perlizadores) nas billas, billas e terminais de ducha eficientes, ou sistemas de dobre descarga nas cisternas.

Os datos sobre caudais de consumo de auga de diferentes equipamentos en 2002 (Soto, 2011) e no período 2014-2016 (Soto et al., 2018) indican unha lixeira redución no tempo. Xa no último período, os caudais de uso das duchas situáronse arredor de 10 litros por minuto, e os das billas de lavabos nunha media de 6,1 litros por minuto. 0 potencial para a redución dos consumos segue a ser moi elevado, pois os equipamentos eficientes nestes usos sitúanse en valores de 4 (duchas), e 2-3 (lavabos) litros por minuto. 


\subsection{CONSUMO DE AUGA NA UDC}

0 consumo global de auga en 2016 na UDC foi de $66.602 \mathrm{~m}^{3}$, lixeiramente inferior ao de anos anteriores. A caída media anual no período 2007-2016 foi do 1,7\% (Soto et al., 2019). En 2014 iniciouse o programa Green Campus en varios centros da UDC, que se foi estendendo nos anos seguintes. Un dos obxectivos deste programa é a realización de auditorías de consumo da auga nos centros acollidos, e a adopción de practicas aforradoras. Xa en 2017, e como resposta á situación de grave seca, a Oficina de Medio Ambiente (OMA) elaborou unha proposta xeral de adopción de medidas de aforro para todos os centros (OMA, 2017), cuxo contido básico se mostra na Figura 1. 0 consumo rexistrado en 2018 foi de $61.088 \mathrm{~m}^{3}$, polo que se conseguiu unha nova redución, do 8,3\% nos dous anos 2017 e 2018 en relación a 2016.

0 documento guía elaborado pola OMA en 2017 contén catro pasos a seguir para adoptar algunhas medidas factibles e de aplicación inmediata para 0 aforro de auga:

- Axustar o fluxo de auga ao mínimo necesario facendo uso da chave de paso asociada a cada billa.

- Colocar un perlizador de baixo consumo, se a billa existente o permite

- Medir os caudais antes e despois e calcular a redución acadada

- Informar ás persoas usuarias e chamar ao uso responsábel da auga.

Partindo da situación actual en moitos centros, vivendas e outros edificios, o potencial e redución do consumo con estas medidas era moi elevado. Para a UDC e 2017 estimouse entre 050 e 0 84\% do consumo de auga nos lavabos (Torrijos et al., 2019). As dúas medidas básicas indicadas apenas presentan custo económico, e se 0 teñen pode recuperarse en pouco tempo polo aforro na factura da auga. Outras medidas que permiten acadar un aforro maior son a muda por billas de baixo consumo, e 0 uso de cisternas de descarga dobre. No caso das cisternas, pódese cambiar unicamente o mecanismo, converténdoas de descarga única en descarga dobre. Na UDC hai unha pequena marxe de actuación neste aspecto, xa que 
existen cisternas de descarga única que poden ser modificadas a dobre descarga. Porén, a maioría dos mecanismos de descarga en retretes son fluxores para os que non existe esa alternativa.
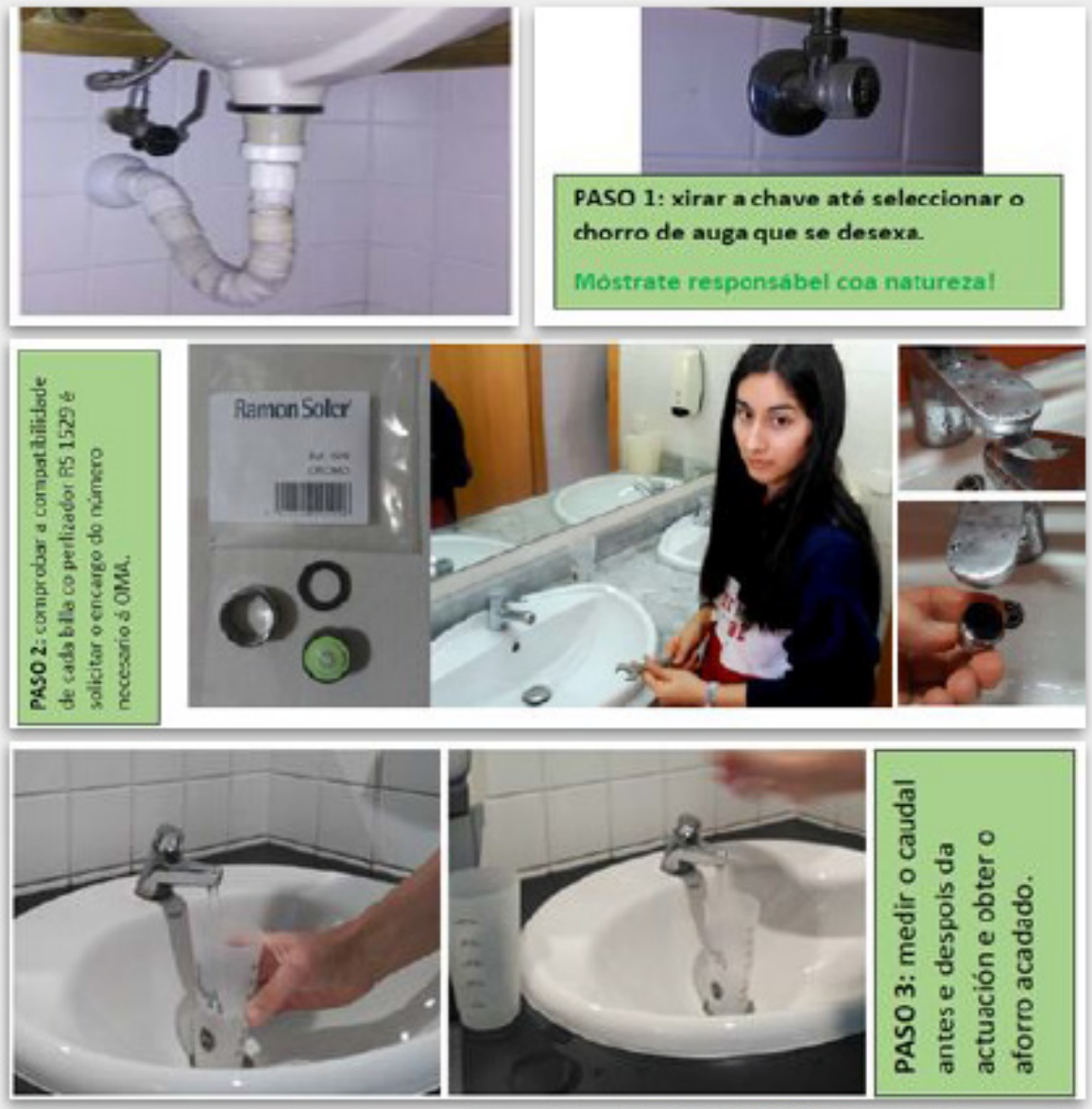

PASO 4: informar a usuarios/as
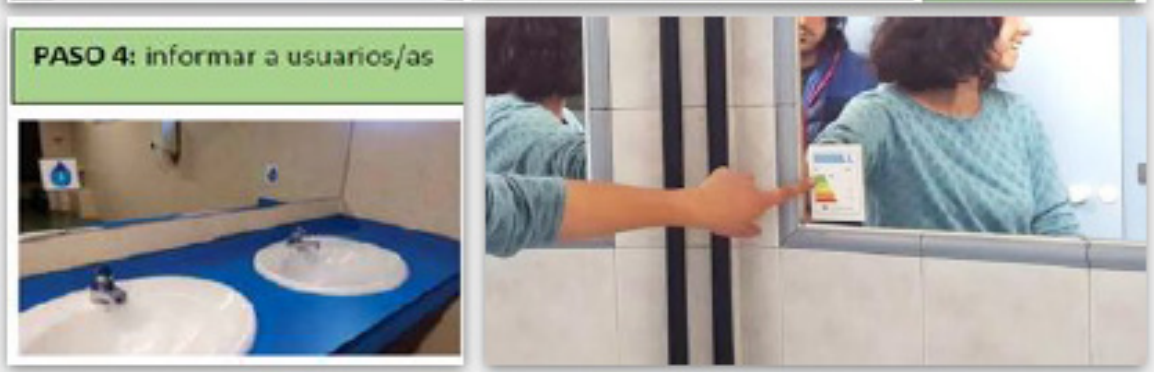

Figura 1. 0 aforro de auga en 4 pasos (OMA, 2017) 


\subsection{OBXECTIVOS}

0 potencial de redución do consumo por modificación dos equipamentos de uso da auga existe tamén na maioría dos centros públicos, e noutros de acceso público como as instalacións de hostalaría, comercios e oficinas en xeral. Raramente estes centros foron aínda obxecto de programas de uso eficiente da auga.

Co obxectivo do traslado desta preocupación ao seo da sociedade, xunto coas prácticas de auditoría da auga e as medidas de redución do consumo, creouse a ferramenta de Emapic de mapeo do consumo da auga na cidade, consistente nunha sinxela auditoría que pode realizar calquera persoa, sexa nos propios equipamentos de uso da auga como naqueles pertencentes a locais de acceso público, e achegar así os datos de consumo de auga que caracterizan os equipamentos existentes.

Participan neste proxecto a OMA, o servizo Emapic e o Grupo de Enxeñaría Química Ambiental, todos eles da Universidade da Coruña. 0 uso inicial desta ferramenta está a facerse dentro das actividades de Educación para a Sustentabilidade do proxecto Campus Casa Cidade que desenvolve a UDC coa colaboración da Fundación Alcoa. Na seguinte sección descríbese 0 contido básico da ferramenta e finalmente preséntanse os primeiros resultados do seu funcionamento.

\section{DESCRICIÓN DA EXPERIENCIA}

\subsection{EMAPIC: REPRESENTAR CARTOGRAFICAMENTE OS COÑECEMENTOS E SENTIMENTOS DA CIDADANÍA}

Emapic é un servizo web desenvolto na UDC para facilitar a localización xeográfica de participantes en investigacións sociais ou mapas de opinión. Ofrece recursos para representar cartograficamente os coñecementos e sentimentos da cidadanía. As súas capacidades desenvólvense máis alá dun servizo de creación de enquisas ao uso, pois é unha ferramenta 
de representación sobre mapas de calquera tipo de dato, facendo fincapé nos procesos colaborativos de participación, facilitando, deste xeito, os procesos de análise das dinámicas sociais.

\subsection{MAPEANDO A EFICIENCIA NO CONSUMO DA AUGA: EMAPIC_AUGA_UDC}

Esta ferramenta é máis unha sinxela auditoría sobre o consumo de auga que unha enquisa. Permite o rexistro do tipo de equipamentos e os caudais de consumo de auga en vivendas particulares e edificios públicos. Ademais das características dos equipamentos, tamén se recolle información relativa a sinalización e información para o consumo responsábel de auga. 0 obxectivo é crear mapas da eficiencia no consumo de auga nas cidade, nas vilas, nos edificios públicos, e por extensión en Galiza, aínda que o seu uso non se limita a ningunha área xeográfica concreta.

A auditoría trata do uso da auga nos aseos ou baños, e inclúe unicamente as billas dos lavabos, tanto as súas características como o caudal, e o tipo de cisternas. A toma de datos é simple e so require dispor dun vaso, graduado ou de volume coñecido, e dun cronómetro. 0 tempo necesario limítase a uns minutos, entre 5 e 10 minutos nun baño típico dunha vivenda ou dun edificio que conte con unha ou un reducido número de unidades de lavado ou cisternas, se ben a ferramenta ofrece diversa información que pode prolongar o tempo empregado. Ofrece tamén os resultados estatísticos xeorreferenciados, a cuxo estudo se poden dedicar moitas horas.

Accédese á ferramenta a través do seguinte enderezo web: https://emapic.es/custom/consumo-auga-udc, onde nos atopamos coas seguintes 5 fiestras ou seccións:

- Fiestra 1: Presentación.

- Fiestra 2 (Figura 2): a) Datos xerais do lugar, incluíndo o nome (opcional) e o tipo (vivenda particular, edificio administrativo, local público, bar...); b) Datos do aseo ou baño (información relativa ao uso responsábel da auga). 
- Fiestra 3 (Figura 3): Datos sobre as billas existentes no aseo (ou aseos dun mesmo edificio), de forma individualizada, podendo introducir tanta billas como se queira: tipo, con/sen perlizador, con/sen chave de regulación do caudal, e datos da medición do caudal.

- Fiestra 4 (Figura 4): Datos sobre as cisternas, tanto o tipo como a existencia de mecanismos aforradores (dobre descarga). Non se pide 0 volume, pola complexidade que podería supor a súa medición.

- Fiestra 5: Sección final cos datos da persoa informante (opcionais) e a xeorreferenciación.

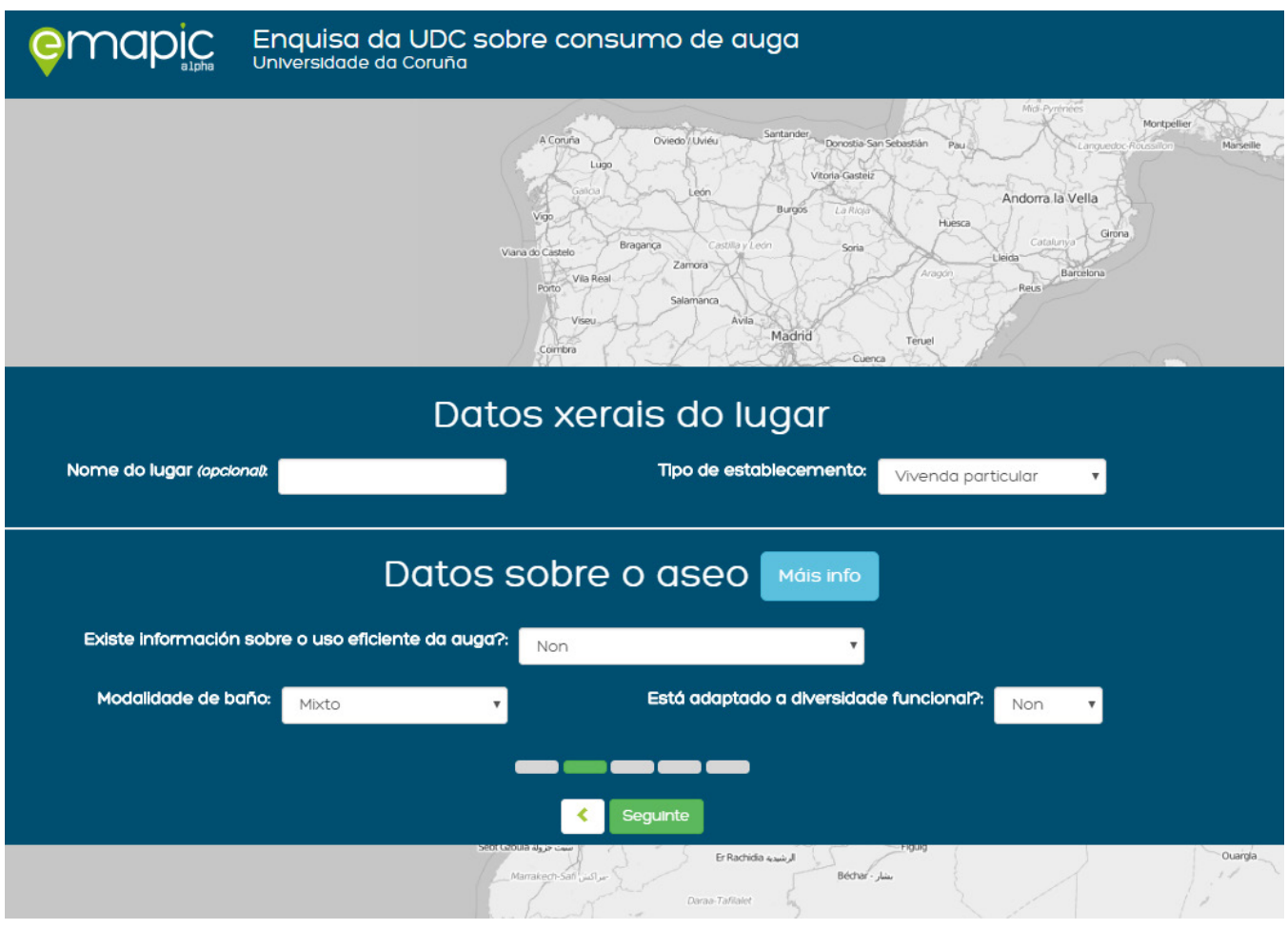

Figura 2. Fiestra para a entrada de datos xerais do lugar e do aseo (ferramenta emapic_auga_UDC "Mapeando a eficiencia no consumo da auga"). 


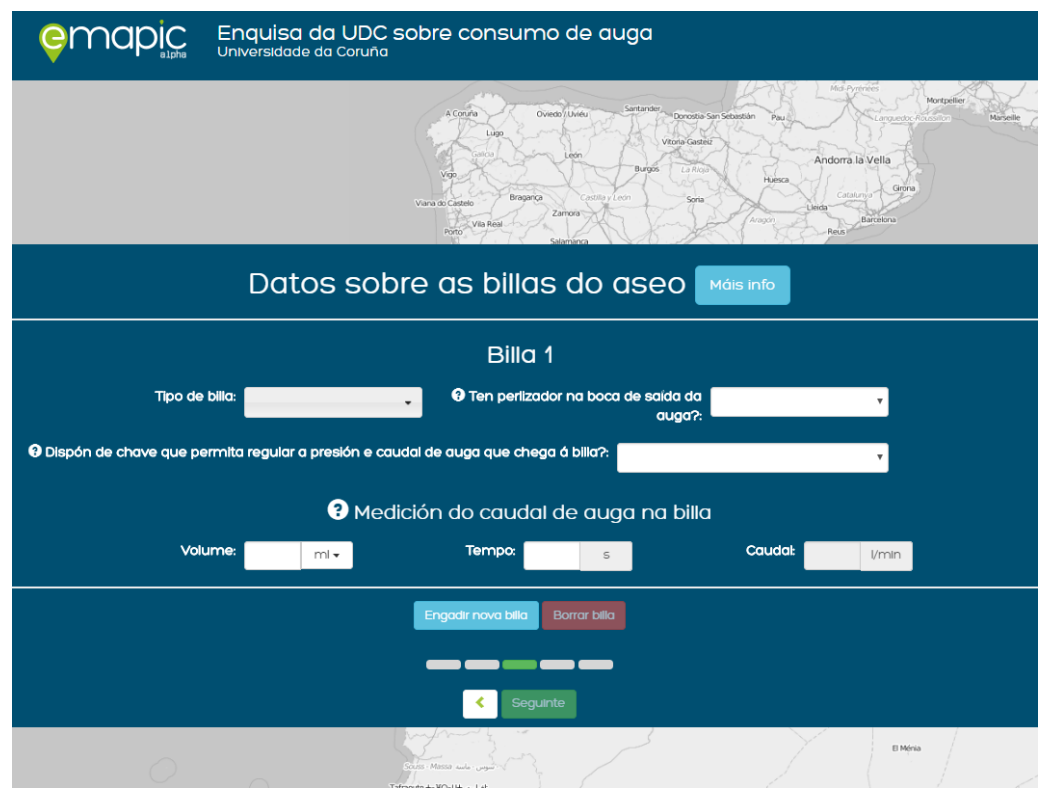

Figura 3. Fiestra para a entrada de datos sobre as billas existentes no aseo (ferramenta emapic_auga_UDC "Mapeando a eficiencia no consumo da auga").

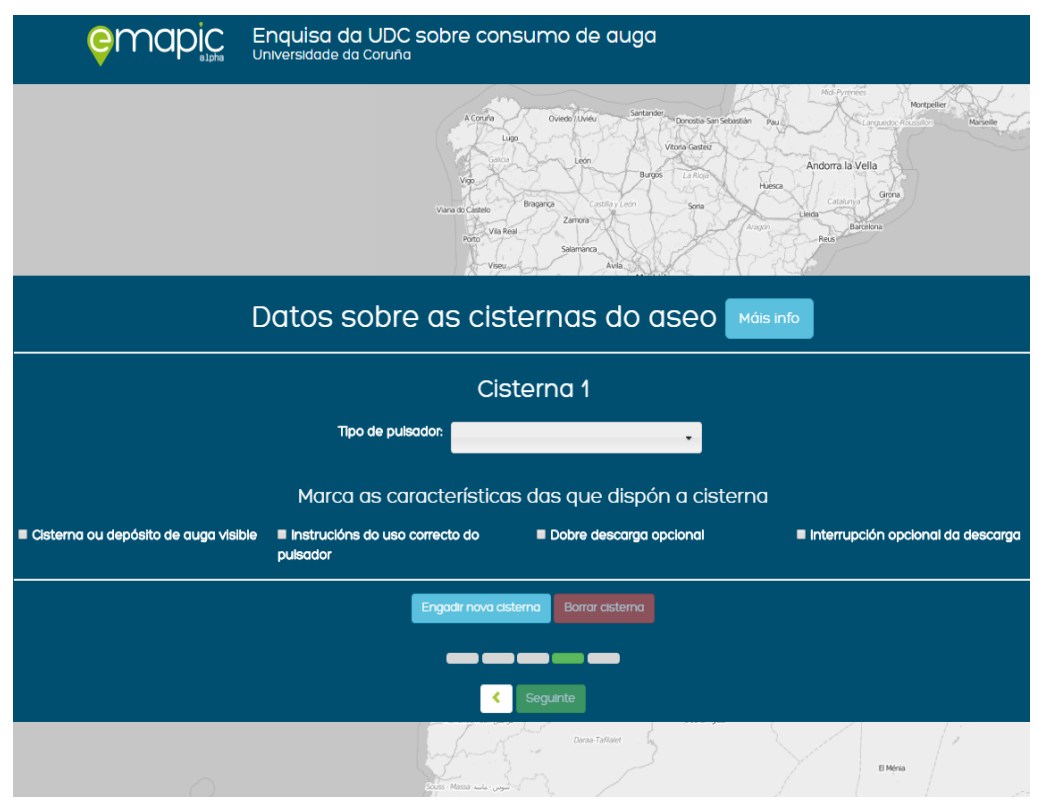

Figura 4. Fiestra para a entrada de datos sobre as cisternas existentes no aseo (ferramenta emapic_auga_UDC “Mapeando a eficiencia no consumo da auga"). 
Ao longo da enquisa inclúe paneis informativos de diverso tipo (iconas "Máis info" e "?"), co obxectivo de dar indicacións sobre un consumo máis eficiente da auga, a diversidade de equipamentos dispoñíbeis, as prácticas e hábitos de aforro e redución da contaminación, a identificación correcta da terminoloxía, ou unhas sinxelas instrucións de medición do caudal (Figura 5).

Na fiestra final, unha vez rexistrados os datos e xeorreferenciada a entrada, o servizo ofrece unha valoración cuantitativa sobre o caso particular que se acaba de introducir, en particular, a posición dos caudais das billas en relación a un caudal de referencia (4 L/min), indicando 0 potencial de redución até 0 óptimo de $2 \mathrm{~L} / \min$ (Clase $\mathrm{A}^{++}$de acordo coa eco-etiqueta desenvolvida pola OMA-UDC). Tamén inclúe unha recomendación en relación ás cisternas no caso de estas non seren de dobre descarga e sobre a conveniencia de contar con información que solicite a colaboración das persoas usuarias no aforro de auga. 

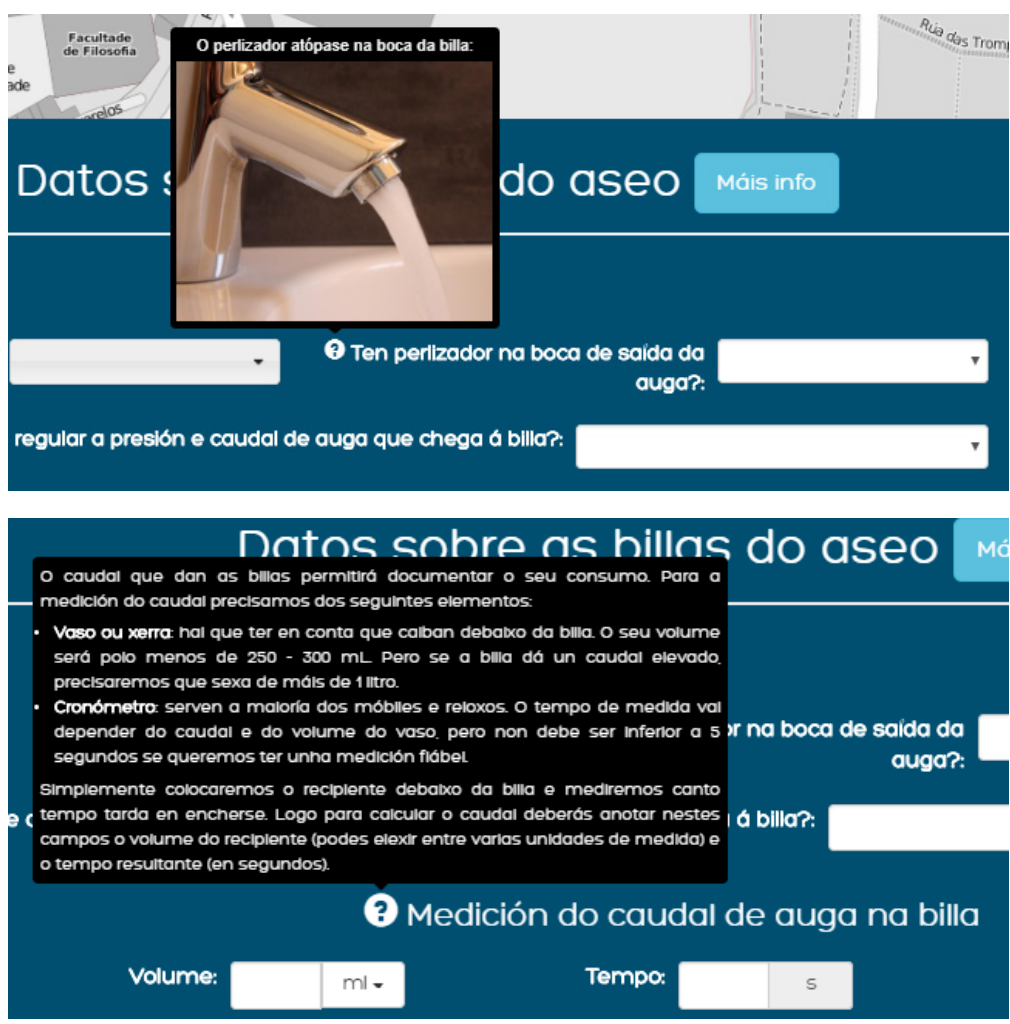

Figura 5. Exemplos de paneis informativos dispoñíbeis nas fiestra da ferramenta emapic_auga_UDC "Mapeando a eficiencia no consumo da auga".

\subsection{O MAPA DA EFICIENCIA NO CONSUMO DA AUGA}

Os resultados acumulados constitúen o mapa de consumo de auga, e pode consultarse na seguinte ligazón: https://emapic.es/custom/consumo-auga-udc/results. A persoa usuaria de emapic_auga_udc ten acceso directo a ver aos resultados desde a última fiestra da enquisa, se ben se pode acceder externamente. Todas as prestacións emapic están a disposición da persoa visitante par ao estudo da información contida no mapa. 0 mapa mostra resultados estatísticos dun número amplo de parámetros para o conxunto de datos ou a selección realizada, que se pode facer seguindo varias vías, como son:

- Para cada un dos diferentes tipos de establecemento

- Xeograficamente, mediante un selector de área 
- Cronoloxicamente, mediante un selector de espazo temporal

- Combinando os tres filtros anteriores

A Figura 6 mostra a localización das ferramentas de filtrado, entre outras moitas dispoñibles en emapic, xunto cun exemplo de mapa para a distribución do tipo de establecemento e a estatística para os caudais de billas.

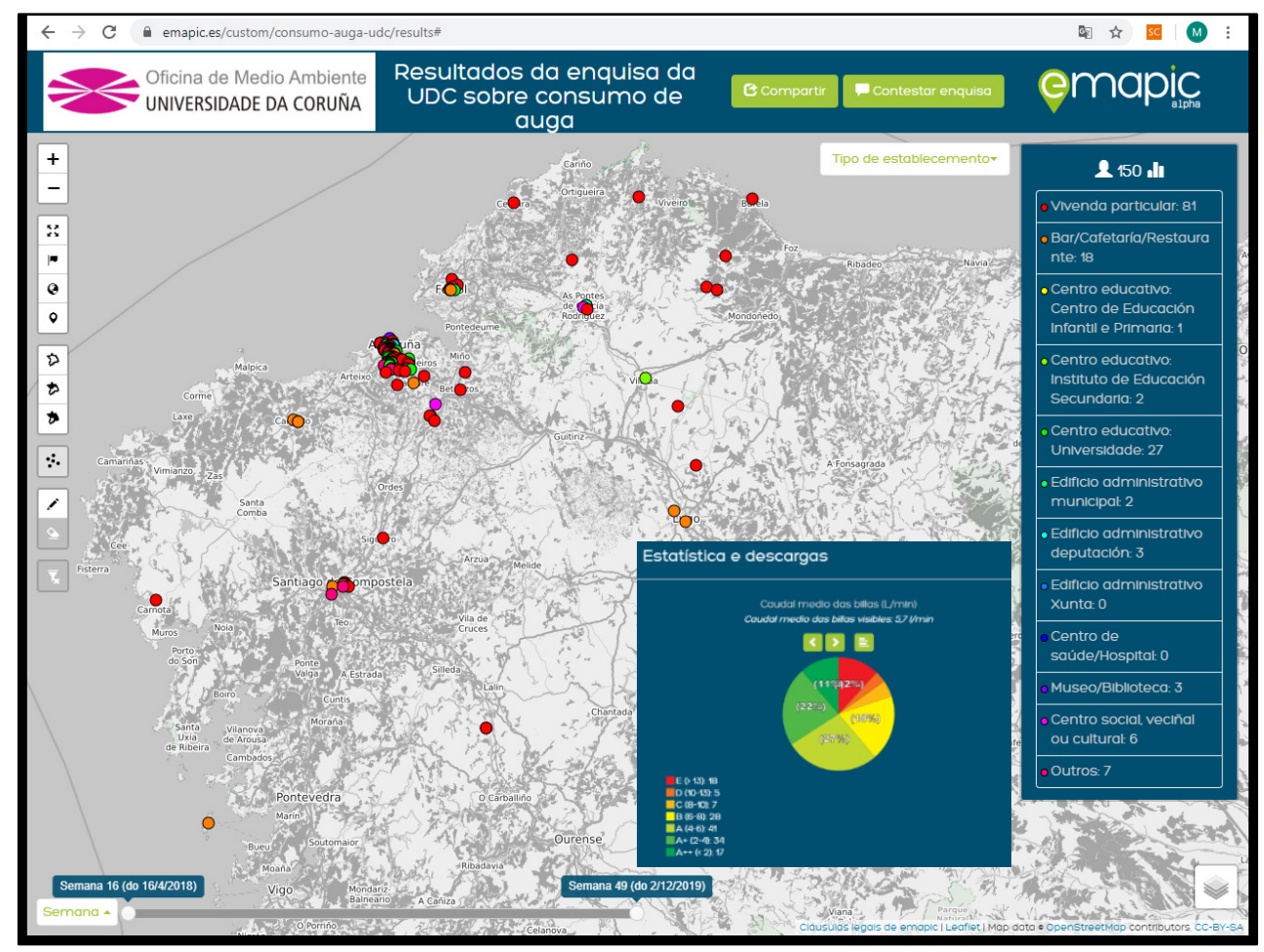

Figura 6. Exemplo presentación de resultados da ferramenta emapic_auga_UDC "Mapeando a eficiencia no consumo da auga". Ferramentas de selección ou filtrado: (1) Selector de tipo de parámetro, (2) selector de filtro xeográfico, (3) selector de espazo temporal, (4) despregue do gráfico de estatística (no recadro sobreposto, exemplo relativo a distribución do caudal das billas).

Emapic permite ademais seleccionar cada entrada particular e visualizar toda a información de detalle correspondente a esa entrada. Isto ten especial interese par ao caso de grandes edificios, nos que pode haber un numero elevado de aseos, billas e cisternas. A Figura 7 mostra un exemplo para un centro da UDC. 


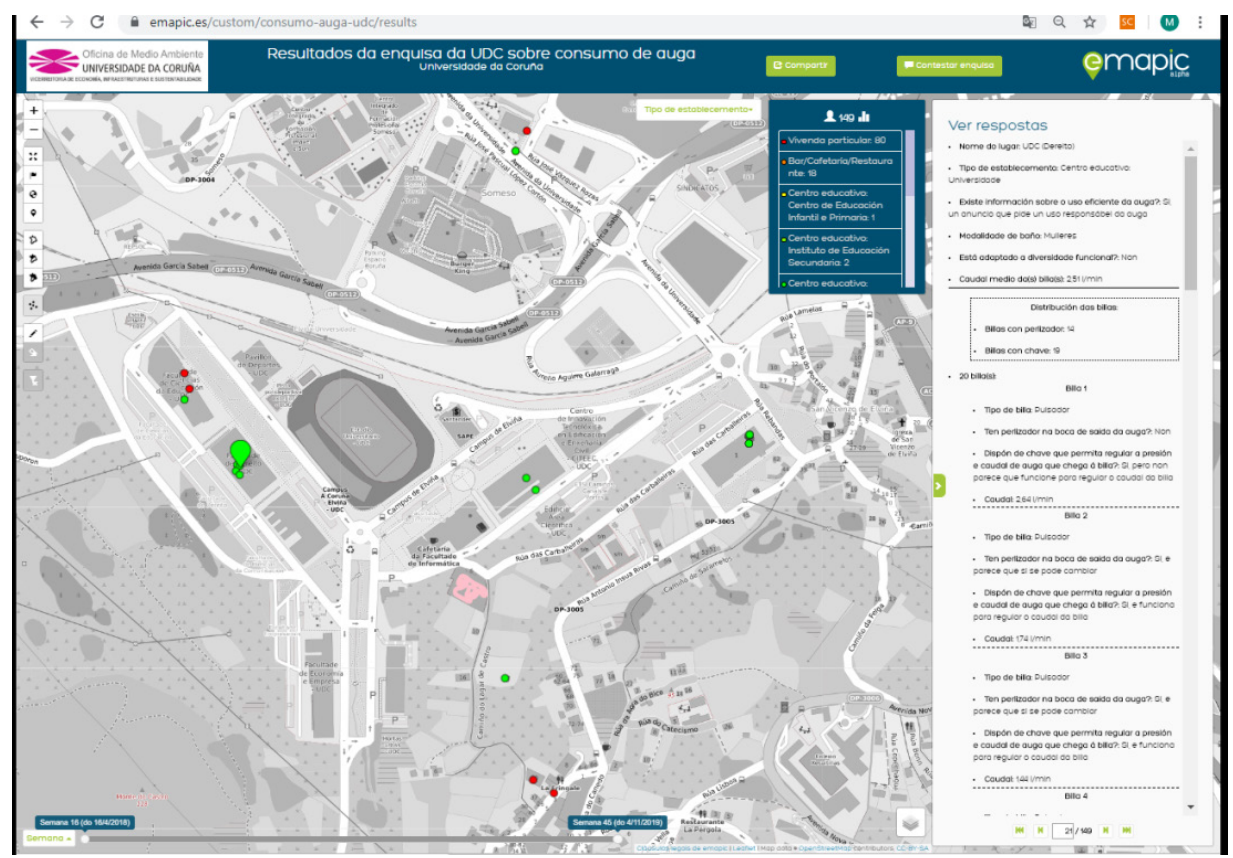

Figura 7. Exemplo presentación de resultados da ferramenta emapic_auga_UDC "Mapeando a eficiencia no consumo da auga". Seleccionada unha entrada para a Facultade de Dereito da UDC, que conta con información relativa a 20 billas deste centro, despregada na columna da esquerda.

Por último, a parte das estatísticas ofrecidas directamente nos mapas emapic, desde a xestión do servizo poden xerarse bases de datos que permitirán un estudo estatístico en máis detalle. Este é un servizo que se ofrece a calquera persoa ou institución que queira facer uso do servizo emapic para un proxecto de mapeado e seguimento da eficiencia do uso da auga no seu centro, edificio ou entidade. A única diferenza para un proxecto organizado é que no final de cada unha das entradas de datos se especifique un mesmo código, que queda rexistrado na base de datos, sen ser público. As persoas responsábeis do proxecto poden solicitar de emapic a base de datos completa que corresponde a todas as entradas dese código, para o seu posterior uso. 


\section{RESULTADOS}

\subsection{ALCANCE DA FERRAMENTA PARA A SENSIBILIZACIÓN AMBIENTAL}

No momento de redactar este artigo, a ferramenta pode considerarse xa definitiva, tras un proceso de mellora ao longo do curso 2018-2019. 0 número de entradas rexistradas (150) é aínda reducido, e atópase localizado maiormente no ámbito de A Coruña. Debido ao seu desenvolvemento inicial nas actividades do curso Campus Casa Cidade, a maioría das entradas corresponden a persoas da comunidade universitaria (67\% estudantes, $11 \%$ PDI, $2 \%$ PAS), mentres $021 \%$ declararon non ter ningunha relación coa UDC.

No outono de 2017 púxose en marcha 0 que foi o precedente desta aplicación, un servizo similar pero destinado a calcular a pegada ecolóxica dos residuos domésticos (Soto e Varela, 2018). Dous anos despois, o mapa da pegada ecolóxica dos residuos conta xa con máis de 1.100 entradas distribuídas por toda Galiza, particularmente no eixo atlántico galego. Esta acollida é proba do interese destas ferramentas, dispoñibles en lingua galega e adaptadas á realidade social e ambiental do país. No caso de emapic_auga_udc falta aínda 0 primeiro lanzamento definitivo, que se agarda teña lugar no que resta do curso 2019-2020.

0 potencial para a sensibilización e a educación ambiental maniféstase é cómprese no momento da utilización da ferramenta por calquera persoa que decida facelo. 0 seu uso require un primeiro achegamento á problemática ambiental e a percepción da corresponsabilidade individual nesa problemática e na adopción alícuota das posibles solucións. Require indagar e investigar sobre 0 estilo de vida e as decisións do día a día que levan a xeración dos impactos ambientais. Alén do uso individual, ambas ferramentas, a calculadora da pegada ecolóxica do lixo como o mapeo da eficiencia no consumo de auga, permiten a realización de mini-proxectos colectivos concibidos para grupos de todo tipo, implicando a elaboración colectiva do proxecto, a implicación individual, e a análise dos resultados nos ámbitos individual e de grupo, así como no marco doutros proxectos similares e do conxunto de entradas aos respectivos mapas emapic. Como xa se indicou, a través do 
uso dun mesmo código para todas as entradas individuais dun mesmo proxecto, o uso colectivo da ferramenta seguirá a ser autónomo e automatizado, sen necesidade de solicitudes de permiso nin intervencións alleas.

0 equipo promotor deste proxecto ten en marcha a elaboración dun grupo de ferramentas que permitan calcular as diferentes compoñentes da pegada ecolóxica. Formarán parte do proxecto as futuras calculadoras da pegada ecolóxica da mobilidade e do consumo de enerxía, que se sumarán á pegada ecolóxica dos residuos xa existente. Agárdase que 0 conxunto de ferramentas se reforce mutuamente.

\subsection{VALIDACIÓN DE RESULTADOS E FUNCIONAMENTO DA FERRAMENTA.}

Tras a súa utilización inicial ao longo do curso 2018-2019, dispomos do primeiro lote de entradas, nun total de 150, que nos permiten proceder a unha validación preliminar. Ao longo deste tempo, como xa se indicou, fóronse mellorando diversos aspectos, e tamén se resolveron os erros de funcionamento inicialmente detectados. A Táboa 1 presenta os primeiros resultados estatísticos para unha serie de parámetros principais.

0 número de entradas en cada ámbito de aplicación (tipo de establecemento) é aínda limitado en moitos deles, particularmente no ámbito do ensino primario e secundario, onde 0 funcionamento da ferramenta pode requirir de revisións futuras. A vivenda particular reúne a maioría das entradas, seguida do ámbito UDC e de instalacións de hostalaría (Táboa 1). Compre observar que o úmero de elementos singulares, tais como billas ou cisternas, pode ser maior que 0 de entradas nun mesmo ámbito. Isto é particularmente notable no caso dos edificios universitarios, onde hai entradas con unha ou varias decenas de elementos. 
Táboa 1. Primeiros resultados estatísticos para unha serie de parámetros principais da ferramenta emapic_auga_UDC "Mapeando a eficiencia no consumo da auga”.

\begin{tabular}{|c|c|c|c|c|c|c|}
\hline & $\begin{array}{c}\text { Vivenda } \\
\text { particular }\end{array}$ & UDC & Hostalaría & $\begin{array}{l}\text { Ensino } 1^{0} \\
\text { e ESO }\end{array}$ & Outros $^{a}$ & Total \\
\hline Tipo de establecemento $\left(\mathrm{n}^{0}\right)$ & 81 & 27 & 18 & 3 & 21 & 150 \\
\hline Tipo de establecemento (\%) & 54 & 18 & 12 & 2 & 14 & 100 \\
\hline $\begin{array}{l}\text { Existe información sobre } 0 \\
\text { uso eficiente da auga (\%) }\end{array}$ & 5 & 34 & 6 & 66 & 9 & 12 \\
\hline $\mathrm{N}^{0}$ Billas & 96 & 95 & 19 & 3 & 37 & 250 \\
\hline $\mathrm{Q}$ medio billas (L/min) & 5,73 & 4.30 & 4.92 & 5,21 & 5,94 & 4,96 \\
\hline Billas con perlizador (\%) & 54 & 52 & 36 & 33 & 55 & 52 \\
\hline Billas con chave (\%) & 76 & 83 & 36 & 66 & 50 & $72^{b}$ \\
\hline $\begin{array}{l}\text { Adaptado a diversidade } \\
\text { funcional }(\%)^{c}\end{array}$ & 14 & 48 & 61 & 66 & 47 & 48 \\
\hline $\mathrm{N}^{0}$ cisternas & 86 & 50 & 19 & 3 & 26 & 184 \\
\hline Cisternas DU (\%) & 45,3 & 90 & 73,7 & 33,3 & 53,8 & 61,4 \\
\hline
\end{tabular}

${ }^{\mathrm{a}}$ As entradas corresponden a centros socio-culturais e edificios administrativos, entre outros. ${ }^{\mathrm{b}} 072 \%$ contan con chave, pero só $052 \%$ se corresponde con chave operativa. ${ }^{c}$ No caso de baños de edificios públicos, refírese ao baño inspeccionado, non a que exista ou non un servizo adaptado próximo.

Os resultados provisionais poñen de manifesto que só existe información relativa ao uso eficiente e responsábel da auga nunha porcentaxe moi reducida dos casos. As cifras indican un $5 \%$ no ámbito da vivenda particular, e un $20 \%$ no resto de establecementos. Todos estes caracterízanse polo uso colectivo dos equipamentos da auga e, descontado o ámbito do ensino polo escaso $\mathrm{n}^{0}$ de entradas, a presenza de distintivos relativos ao uso eficiente da auga e chamar a un uso responsábel é aínda moi limitada. Na UDC chegaba, na mostra incluída no mapa, a un $34 \%$, se ben o programa Green Campus ten mellorado esta situación particularmente ao longo do último curso académico. A sinalética empregada a UDC é diversa, xa que diferentes programas teñen feito ou están a facer deseños específicos. Na Figura 8 móstranse os elementos que a OMA ven de elaborar no último curso, en paralelo co desenvolver do servizo emapic_auga_udc. Para a elaboración da eco-etiqueta de uso eficiente da auga, partiuse da idea da eco-etiqueta enerxética e da menos coñecida eco-etiqueta da auga (EWL, 2018). 

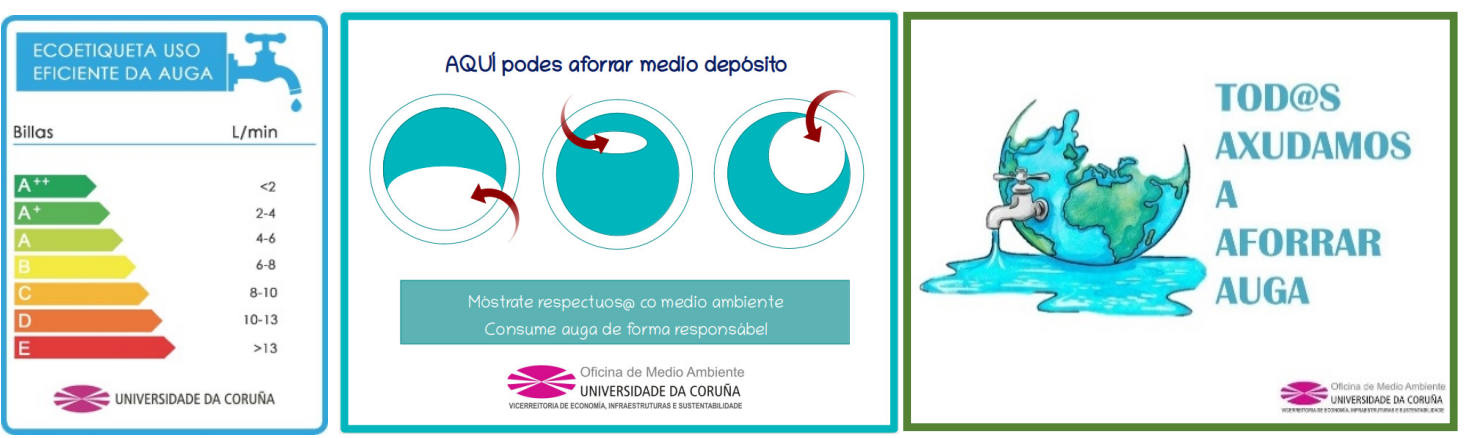

Figura 8. Eco-etiqueta e outros adhesivos desenvolvidos para a sinalización do consumo de auga nas billas da UDC (OMA).

0 caudal medio das billas variou relativamente pouco, entre os $4,3 \mathrm{~L} / \mathrm{min}$ na UDC e 0 s 5,9 L/min no capítulo "outros", cunha media de 5,0 L/min (Táboa 1). Nesta estatísticas excluíronse 3 valores anómalos dun total de 250 entradas ( $n^{0}$ de billas). Correspondían con caudais de 30, 70 e $100 \mathrm{~L} / \mathrm{min}$, pouco probables ou mesmo claramente errados en base a consideracións de tipo físico. Os resto de valores atópanse dentro dos rangos válidos e esperables. A Táboa 2 mostra as porcentaxes de billas que se agrupan nunha das tres categorías de ecoeficiencia indicadas. Entre 014 e 0 52\% das billas, segundo 0 ámbito, corresponderían cun modelo eco-eficiente tipo $\mathrm{A}+$ ou mellor (caudal menor de $4 \mathrm{~L} / \mathrm{min}$ ). Os datos indican que o potencial de mellora segue a ser moi elevado. As billas con perlizador $\mathrm{e}$ as billas con chave operativa roldaban aproximadamente $050 \%$ (Táboa 1). No que se refire ás cisternas, 0 62\% do total era contaban aínda con mecanismo de descarga única.

Táboa 2. Porcentaxes de billas que se agrupan en cada nunha das tres categorías de ecoeficiencia.

\begin{tabular}{cccccc}
\hline Clase eco de billas, en \% & $\begin{array}{c}\text { Vivenda } \\
\text { particular }\end{array}$ & Universidade & Hostalaría & $\begin{array}{c}\text { Ensino } 1^{0} \\
\text { e ESO }\end{array}$ & Outros \\
\hline A+ ou mellor $(<4 \mathrm{~L} / \mathrm{min})$ & 34,6 & 51,9 & 27,8 & 33,3 & 14,3 \\
\hline A $(4+6 \mathrm{~L} / \mathrm{min})$ & 29,6 & 14,8 & 38,9 & 0,0 & 28,6 \\
\hline B ou peor $(>6 \mathrm{~L} / \mathrm{min})$ & 35,8 & 33,3 & 33,3 & 66,7 & 57,1 \\
\hline Total & 100 & 100 & 100 & 100 & 100 \\
\hline
\end{tabular}




\section{CONCLUSIÓNS}

Dispomos desta ferramenta accesible na ligazón https://emapic.es/custom/consumo-augaudc. É unha aplicación online enfocada ao análise, medición e rexistro dos equipamentos de uso da auga, avaliándoos en función das alternativas de equipamentos eco-eficientes. Caracterízase por unha realización moi simple, que pode ser acometida por calquera persoa, e que se pode levar a cabo tanto no ámbito doméstico como en diferentes locais de acceso público.

De utilidade para educación ambiental e sensibilización no uso da auga, a ferramenta emapic_auga_udc permite analizar un diverso grupo de indicadores, e acceder aos datos individuais de cada entrada directamente sobre o mapa, ou de forma agrupada en función de diferentes filtros e selectores. Aliás, permite aos responsábeis rexistrados obter unha base de datos co obxectivo de posteriores análises dos resultados. Este servizo ofrécese a grupos organizados que queiran facer uso da ferramenta, para o que abonda con empregar un código que permitirá posteriormente baixar os datos correspondente e o seu envío a quen corresponda.

\section{REFERENCIAS}

Díaz-Fierros, F. (2007). Cambio climático: A paisaxe galega do interior transfórmase na do Douro portugués. Cerna n $n^{0}$ 52, pp. 29-32.

EWL (2018). European Water Label. http://www.europeanwaterlabel.eu/ (último acceso: 17/01/2020).

IGE (2018). Instituto Galego de Estatística. https://www.ige.eu/ (consulta 17/01/2020).

Malvar, F., Baqueiro-Vidal, M., Soto, M. (2018). Seca e xestión da auga en Vigo: o proxecto de nova captación no río Verdugo. X Congresso Ibérico de Gestão e Planeamento da Água. Coimbra, 06-08/09/2018. 
OMA (2017). Medidas a tomar nos centros da UDC co obxectivo de reducir o consumo de auga. Accesible en: https://www.udc.es/sociedade/medio_ambiente/auga_e_rios/ (último acceso: 17/01/2020).

Soto, M. (2011). Auditoría da auga dirixida á minimización como actividade para a ambientalización curricular. II Congreso Internacional de Docencia Universitaria, Vigo. 30/06 a 02/07/2011.

Soto, M., Varela-García, F.A., Torrijos, V., Calvo, D. (2018). Auditoría e mapeo do consumo de auga: do fogar aos centros de estudo e o Ámbito urbano. $X$ Congresso Ibérico de Gestão e Planeamento da Água. Coimbra, 06-08/09/2018.

Soto, M., Varela, A. (2018). UDC residuo cero. Calculadora online da pegada ecolóxica. En: De la Torre Fernández, E. (ed.). Contextos universitarios transformadores: retos e ideas innovadoras, pp. 207-224. II Xornadas de Innovación Docente. Cufie. Universidade da Coruña. D0l: https://doi.org/10.17979/spudc.9788497496780.

Soto, M., Martinez-Gil, F.J. (2006). 0 tempo dos ríos. Servizo de Publicacións da Universidade da Coruña, 355 pp. A Coruña.

Torrijos, V., Soto, M., Calvo, D. (2019). Sostauga project: reduction of water consumption and evaluation of potential uses for endogenous resources. International Symposium: Accelerating The Implementation Of Sustainable Development In Campus Activities And Programmes. Haw Hamburg, Manchester Metropolitan University, IUSDRP, ESSSR, UDC. A Coruña, 2-3/12/2019. 